\title{
Neutrophil Gelatinase-Associated Lipocalin: A New Marker of Renal Function in C-Related End Stage Liver Disease
}

\author{
Omkolsoum Mohamed Alhaddad, ${ }^{1}$ Ayman Alsebaey, ${ }^{1}$ Mohamed Omar Amer, ${ }^{1}$ \\ Hala Hany El-Said, ${ }^{2}$ and Tary Abdel Hamid Salman ${ }^{1}$ \\ ${ }^{1}$ Department of Hepatology, National Liver Institute, Menoufiya University, Shebeen El-Kom, Egypt \\ ${ }^{2}$ Department of Clinical Biochemistry, National Liver Institute, Menoufiya University, Shebeen El-Kom, Egypt
}

Correspondence should be addressed to Omkolsoum Mohamed Alhaddad; dromkolsoum@yahoo.com

Received 16 April 2015; Revised 15 June 2015; Accepted 16 June 2015

Academic Editor: Haruhiko Sugimura

Copyright (C) 2015 Omkolsoum Mohamed Alhaddad et al. This is an open access article distributed under the Creative Commons Attribution License, which permits unrestricted use, distribution, and reproduction in any medium, provided the original work is properly cited.

\begin{abstract}
Background/Aims. Renal impairment is a common complication of cirrhosis. Serum creatinine is less sensitive in these patients. Measurement of the glomerular filtration rate (GFR) is the gold standard but time consuming. The aim is to validate plasma NGAL (pNGAL) and urinary NGAL (uNGAL) as markers of renal function in patients with HCV related cirrhosis. Patient and Methods. One hundred HCV related end stage liver cirrhosis patients were randomized into two groups: Group I $(n=35)$, patients with GFR $<60 \mathrm{~mL} / \mathrm{m}$ measured by isotope scanning of the kidney (Renogram), and Group II $(n=65)$, patients with GFR $\geq 60 \mathrm{~mL} / \mathrm{m}$. The pNGAL and uNGAL were measured within 2 days of the Renogram. Results. Both groups were matched with age, sex, and Child Pugh score. There was statistically significant difference between both groups regarding serum creatinine (1.98 \pm 1.04 versus $1.38 \pm 0.88 \mathrm{mg} / \mathrm{dL} ; p=0.003)$ and pNGAL level $(5.79 \pm 2.06$ versus $7.25 \pm 3.30 \mathrm{ng} / \mathrm{dL} ; p=0.019)$. Both groups were comparable $(p>0.05)$ for the uNGAL $(6.00 \pm 0.78$ versus $6.03 \pm 0.96 \mathrm{ng} / \mathrm{mL})$. Unlike uNGAL, the pNGAL positively correlated with total GFR by Renogram $(r=0.3 ; p=0.001)$. With a cutoff $\geq 4 \mathrm{ng} / \mathrm{mL}$, pNGAL had $94.3 \%$ sensitivity and $1.5 \%$ specificity and PPV $=34$, $\mathrm{NPV}=33.3, \mathrm{LR}+=-175.1$, and $\mathrm{LR}-=-60.6$. Conclusion. The $\mathrm{pNGAL}$ is a promising marker of the renal function in patients with cirrhosis.
\end{abstract}

\section{Introduction}

Liver cirrhosis is a dreadful complication of chronic HCV infection. It is complicated with the occurrence of esophageal varices, ascites, spontaneous bacterial peritonitis, dilutional hyponatremia, and hepatorenal syndrome (HRS) [1].

Renal impairment especially acute kidney injury (AKI) is commonly seen in patients with cirrhosis with increased risk of mortality [2]. It is usually precipitated by variceal bleeding, diuretics overuse, nephrotoxic drugs, for example, aminoglycosides, contrast media nephropathy, and abdominal paracentesis $[2,3]$.

Chronic kidney disease (CKD) is also seen in HCV related cirrhosis [4]. It is ascribed to the cryoglobulinemia and membranoproliferative glomerulonephritis [5]. Serum creatinine is the standard marker of the renal functions.
It is synthetized in the liver as creatine, phosphorylated in the muscle to creatinine, to be removed by the kidney through filtration and active secretion. It is affected by age, gender, muscle mass, protein diet, and liver condition $[6,7]$.

Although it is commonly used to assess the renal function, it is a nonsensitive marker for renal dysfunction in patients with liver cirrhosis. This is due to decreased hepatic formation, malnutrition, loss of the muscle mass, and decreased secretion with spironolactone use. In addition, high bilirubin level impairs accurate measurement of serum creatinine by spectrophotometry (Jaffè method) $[8,9]$. So, normal creatinine does not exclude renal impairment. Seeking for another surrogate is warranted.

Neutrophil gelatinase-associated lipocalin (NGAL) is $25 \mathrm{kDa}$ protein of the lipocalin family [10]. It is synthesized in renal tubular, intestinal, hepatic, and pulmonary tissue. 
Its synthesis is upregulated markedly in tissue injury especially the kidney [11]. Circulating NGAL is filtered by the glomerulus to be reabsorbed in the proximal tubule. It is secreted in low concentrations by the thick ascending limb of the renal tubule $[11,12]$. It can be measured in the serum and urine [13].

In proximal tubular injury, increased NGAL synthesis and decreased reabsorption occur causing increased urinary levels $[12,14]$. In distal tubular injury there is increased distal renal tubular expression and synthesis of NGAL and NGAL secretion increases, increasing urinary levels as well $[12,15$, 16].

In AKI, plasma NGAL levels rise, related to either concomitant hepatic, pulmonary, or intestinal tissue injury, coupled with decreased glomerular filtration of NGAL [11].

NGAL is a good predictor of AKI development, severity, and therapeutic monitoring [17] especially with postcardiac surgery, sepsis, renal replacement therapy, and rejection after kidney transplantation, reviewed in detail by Shemin and Dworkin and Haase et al. [11, 12].

This study aimed to validate plasma NGAL (pNGAL) and urinary NGAL (uNGAL) as markers of renal function in patients with HCV related cirrhosis.

\section{Patients and Methods}

This study was conducted in National Liver Institute hospitals, Menoufiya University, Egypt, after ethics committee approval and obtaining an informed consent from all the enrolled subjects.

One hundred HCV related end stage liver cirrhosis patients were included. All of them underwent isotope kidney scanning (Renogram) for the assessment of the glomerular filtration rate (GFR). They were divided into 2 groups by the GFR value: Group I $(n=35)$, patients with GFR $<60 \mathrm{~mL} / \mathrm{m}$, and Group II $(n=65)$, patients with GFR $\geq 60 \mathrm{~mL} / \mathrm{m}$.

The exclusion criteria were sepsis, GIT bleeding, concurrent medical disease such as long standing diabetes mellitus or hypertension, advanced intrinsic kidney disease as evidenced by small kidneys on ultrasound or morphological changes in static isotopic studies, solid organ transplantation, malignancy, and history of nephrotoxic drug administration.

All the patients underwent thorough history taking and physical examination. The following laboratory tests were done: liver function tests, blood urea, serum creatinine, serum sodium, serum potassium, CBC, and random blood sugar. Furthermore, abdominal ultrasonography with Doppler on the renal arteries for measuring the renal resistive index (RI) of both kidneys was done.

2.1. Sample Collection and Storage. For plasma and urinary NGAL measurement, blood and urine samples were collected within 2 days of the Renogram. Blood samples were drawn at the predetermined time points and processed within 2 hours after collection. Blood collected in serum separator tubes was allowed to clot for 15 to 20 minutes and then centrifuged for 12 minutes at $1000 \mathrm{~g}$. Serum was collected and subsequently frozen at -80 Celsius until further analysis. Urine samples were centrifuged and the supernatant was collected and subsequently frozen at -80 Celsius until further analysis.

2.2. NGAL Analysis in Blood and Urine. All samples were analyzed in batches in a random fashion. The serum and urine NGAL level were performed using one of the commercially available assays (Wkea Med Supplies Corp.) that specifically detect human NGAL. The assay was performed as per the manufacturer's protocol. Briefly, $100 \mu \mathrm{L}$ of NGAL standards or diluted samples were applied onto the precoated microwells in duplicate. Microwells were then incubated for $1 \mathrm{~h}$ at room temperature and then washed with washing buffer. Finally, NGAL concentration was measured at $450 \mathrm{~nm}$ wavelength in each well. Urine creatinine was measured to standardize urinary NGAL for changes in urine concentration. Urinary NGAL excretion was presented as the amount of urinary NGAL in ng per mL urine as well as in ng per mg of urine creatinine to correct for differences in NGAL due to urine dilution. The laboratory investigators were blinded to the sample sources and clinical outcomes until the end of the study $[18,19]$.

2.3. Isotope Scanning of the Kidney. Tc-99m DMSA static renal scan; anterior, posterior, and posterior oblique views on the abdominopelvic region were acquired 3 hours after injection of $5 \mathrm{mCi}$ of the tracer. Tc-99m DTPA dynamic renal scan; dynamic posterior views on the abdominopelvic region were acquired immediately after injection of $8 \mathrm{mCi}$ of the tracer for $30 \mathrm{~min}$, and I.V lasix was injected at the middle of the study. Then Renograms and renal function indices were generated. Delayed images were taken at 4 and 24 hours after injection.

2.4. Statistical Analysis. Data was statistically analyzed using IBM SPSS Statistics version 21 for Windows. Data are expressed as mean \pm standard deviation. All $p$ values are 2 tailed, with values $<0.05$ considered statistically significant. Comparisons between two groups were performed using Student's $t$-test for parametric data and Mann-Whitney test for nonparametric data. The linear relationship between two variables was analyzed by the correlation coefficient $(r)$ (Pearson for parametric data and Spearman for nonparametric data). Univariate binary logistic regression was done for detecting the predictors of the GFR below $60 \mathrm{~mL} / \mathrm{m}$. The receiver operating characteristic (ROC) curve analysis was used for detection of the cutoff value of the plasma and urinary NGAL levels. Sensitivity, specificity, positive predictive value, negative predictive value, likelihood ratio positive, and likelihood ratio negative were used to express the cutoff. A value of $0.5-0.59$ is of no useful performance for discrimination of the outcome under assessment.

\section{Results}

As shown in Table 1, both groups were matched for the age and gender. There was no statistically significant difference ( $p>0.05)$ between Groups I and II regarding the MAP, CTP score, total bilirubin, serum albumin, AST, ALT, WBCs, platelets, and the INR. 
TABLE 1: Comparison of the baseline data in both groups.

\begin{tabular}{lccc}
\hline & Group I & Group II & \\
& GFR $<60 \mathrm{~mL} / \mathrm{m}$ & GFR $\geq 60 \mathrm{~mL} / \mathrm{m}$ & $p$ \\
& $N=35$ & $N=65$ & \\
& $\mathrm{M} \pm \mathrm{SD}$ & $\mathrm{M} \pm \mathrm{SD}$ & \\
\hline Age $($ years $)$ & $51.17 \pm 7.61$ & $47.80 \pm 8.90$ & 0.06 \\
Gender & & & \\
$\quad$ Female $(N)$ & 8 & 9 & 0.26 \\
$\quad$ Male $(N)$ & 27 & 56 & \\
MAP $(\mathrm{mmHg})$ & $80.86 \pm 6.48$ & $80.46 \pm 6.87$ & 0.780 \\
CTP score & $10.14 \pm 1.48$ & $10.08 \pm 1.46$ & 0.831 \\
MELD & $23.71 \pm 3.99$ & $20.09 \pm 5.78$ & $0.002^{*}$ \\
MELD Na & $28.40 \pm 3.22$ & $25.69 \pm 5.62$ & $0.025^{*}$ \\
Total bilirubin $(\mathrm{mg} / \mathrm{dL})^{\S}$ & $5.45 \pm 5.64$ & $4.16 \pm 3.20$ & 0.450 \\
Albumin $(\mathrm{g} / \mathrm{dL})$ & $2.48 \pm 0.50$ & $2.44 \pm 0.45$ & 0.733 \\
AST $(\mathrm{u} / \mathrm{L})$ & $74.11 \pm 43.30$ & $75.67 \pm 43.51$ & 0.865 \\
ALT $(\mathrm{u} / \mathrm{L})$ & $49.83 \pm 26.90$ & $52.62 \pm 30.80$ & 0.653 \\
Hemoglobin $(\mathrm{g} / \mathrm{dL})^{\S}$ & $9.60 \pm 1.03$ & $10.54 \pm 1.64$ & $0.003^{*}$ \\
WBCs $\times 10^{3} / \mu \mathrm{L}$ & $5.60 \pm 3.19$ & $5.74 \pm 3.22$ & 0.831 \\
Platelets $\times 10^{3} / \mu \mathrm{L}$ & $103.57 \pm 26.29$ & $93.12 \pm 51.53$ & 0.265 \\
INR & $1.77 \pm 0.30$ & $1.69 \pm 0.27$ & 0.195 \\
\hline
\end{tabular}

$\overline{{ }^{9} \text { Mann-Whitney } U \text { test, GFR: glomerular filtration rate, MAP: mean arterial }}$ pressure, CTP: Child Pugh score, and MELD: model of end stage liver disease; ${ }^{*} p<0.05$.

However, a statistically significant difference was found between both groups regarding the MELD $(23.71 \pm 3.99$ versus $20.09 \pm 5.78 ; p=0.002)$, MELD Na $(28.40 \pm 3.22$ versus $25.69 \pm 5.62 ; p=0.025)$, and the hemoglobin level $(9.60 \pm 1.03$ versus $10.54 \pm 1.64 \mathrm{~g} / \mathrm{dL} ; p=0.003)$.

Table 2 demonstrates the parameters of assessment of the renal function. There was a statistically significant difference between Groups I and II regarding the blood urea (101.94 \pm 47.57 versus $78.23 \pm 53.15 \mathrm{mg} / \mathrm{dL} ; p=0.03$ ) and serum creatinine $(1.98 \pm 1.04$ versus $1.38 \pm 0.88 \mathrm{mg} / \mathrm{dL} ; p=0.003)$ unlike serum sodium and potassium. The renal resistive index measurement was not helpful as the values were comparable in both groups.

The pNGAL level was statistically significant between Groups I and II $(5.79 \pm 2.06$ versus $7.25 \pm 3.30 \mathrm{ng} / \mathrm{mL} ; p=$ $0.019)$ contrary to uNGAL which was comparable between both groups without a significantly statistical difference $(6.00 \pm 0.78$ versus $6.03 \pm 0.96 \mathrm{ng} / \mathrm{mL} ; p=0.866)$.

The pNGAL level positively correlated with the GFR value measured by Renogram ( $r=0.3 ; p=0.001)$ unlike the uNGAL $(r=0.01 ; p=0.848)$.

The ROC curve analysis (Table 3 and Figure 1) revealed that the pNGAL was useful for detecting GFR below $60 \mathrm{~mL} / \mathrm{m}$ (AUC 0.269; $p=0.001$ ), unlike the uNGAL (AUC 0.459; $p=$ 0.497).

The pNGAL is only a good positive test. A cutoff of 4 is associated with $94.3 \%$ sensitivity and $1.5 \%$ specificity and $\mathrm{PPV}=34, \mathrm{NPV}=33.3, \mathrm{LR}+=-175.1$, and $\mathrm{LR}-=-60.6 . \mathrm{A}$ cutoff of 5.3 is associated with $65.7 \%$ sensitivity and $13.8 \%$
TABLE 2: Comparison of the renal function parameters in both groups.

\begin{tabular}{lccc}
\hline & Group I & Group II & \\
& $\mathrm{GFR}<60 \mathrm{~mL} / \mathrm{m}$ & $\mathrm{GFR} \geq 60 \mathrm{~mL} / \mathrm{m}$ & \\
& $\mathrm{M} \pm \mathrm{SD}$ & $\mathrm{M}=65$ & $p$ \\
& $101.94 \pm 47.57$ & $78.23 \pm 53.15$ & $0.03^{*}$ \\
\hline $\begin{array}{l}\text { Urea }(\mathrm{mg} / \mathrm{dL}) \\
\text { Creatinine }(\mathrm{mg} / \mathrm{dL})\end{array}$ & $1.98 \pm 1.04$ & $1.38 \pm 0.88$ & $0.003^{*}$ \\
$\begin{array}{l}\text { Serum sodium } \\
\text { (mmol/L) }\end{array}$ & $127.46 \pm 4.56$ & $124.92 \pm 16.50$ & 0.376 \\
$\begin{array}{l}\text { Serum potassium } \\
\text { (mmol/L) }\end{array}$ & $4.31 \pm 0.75$ & $6.11 \pm 14.99$ & 0.482 \\
$\begin{array}{l}\text { Right kidney resistive } \\
\text { index }\end{array}$ & $0.68 \pm 0.06$ & $0.66 \pm 0.05$ & 0.096 \\
$\begin{array}{l}\text { Left kidney resistive } \\
\text { index }\end{array}$ & $0.66 \pm 0.04$ & $0.66 \pm 0.05$ & 0.677 \\
pNGAL (ng/mL) & $5.79 \pm 2.06$ & $7.25 \pm 3.30$ & $0.019^{*}$ \\
uNGAL (ng/mL) & $6.00 \pm 0.78$ & $6.03 \pm 0.96$ & 0.866 \\
\hline${ }^{\circledR}$ Mann-Whitney $U$ test; ${ }^{*} p<0.05$. & &
\end{tabular}

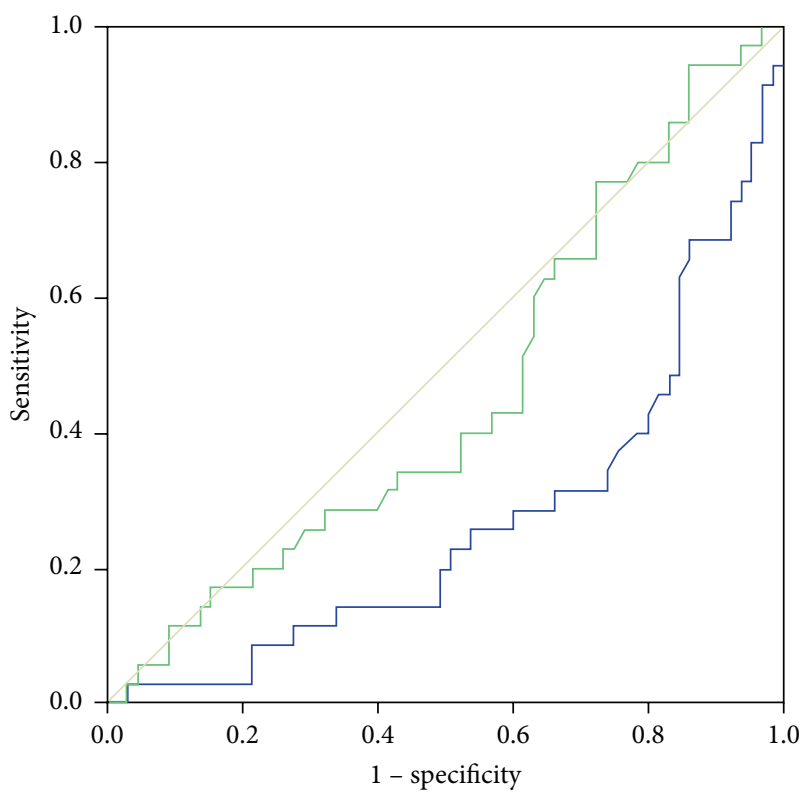

Source of the curve

- pNGAL

- uNGAL

_ Reference line

FIGURE 1: The receiver operating characteristic (ROC) curve analysis of pNGAL $(p=0.001)$ and uNGAL $(p>0.05)$.

specificity and PPV $=29.1, \mathrm{NPV}=42.9, \mathrm{LR}+=-5.11$, and $\mathrm{LR}-$ $=-4.7$.

By using the logistic regression analysis the blood urea, serum creatinine, MELD, MELD Na, and pNGAL levels were predictors of the GFR below $60 \mathrm{~mL} / \mathrm{m}$.

By correlation analysis the total GFR correlated with serum creatinine $(r=-5.25 ; p=0.001)$, pNGAL $(r=0.329$; 
TABLE 3: ROC curve analysis of both pNGAL and uNGAL levels.

(a)

\begin{tabular}{lcccc}
\hline & \multicolumn{2}{c}{ Area under the curve } & \multicolumn{2}{c}{ Asymptotic 95\% confidence interval } \\
& Area & $p$ & Lower bound & Upper bound \\
\hline pNGAL & 0.269 & $0.001^{*}$ & 0.164 & 0.373 \\
uNGAL & 0.459 & 0.497 & 0.341 & 0.577 \\
\hline
\end{tabular}

(b)

\begin{tabular}{lcccccc}
\hline pNGAL cutoff & Sensitivity & Specificity & PPV & NPV & LR+ & LR- \\
\hline $4 \mathrm{ng} / \mathrm{mL}$ & $94.3 \%$ & $1.5 \%$ & 34 & 33.3 & -175.1 & -60.6 \\
$5.3 \mathrm{~g} / \mathrm{mL}$ & $65.7 \%$ & $13.8 \%$ & 29.1 & 42.9 & -5.11 & -4.7 \\
\hline
\end{tabular}

PPV: positive predictive value, NPP: negative predictive value, and LR: likelihood ratio; ${ }^{*} p<0.05$.

$p=0.001), \operatorname{MELD}(r=-0.525 ; p=0.001)$, and MELD Na $(r=-0.427 ; p=0.001)$ unlike uNGAL $(r=-0.182$; $p=0.07)$. The serum creatinine did not correlate with either pNGAL $(r=-0.120 ; p=0.236)$ or uNGAL $(r=0.019 ; p=$ $0.848)$. The MELD score correlated with serum creatinine $(r=0.702 ; p=0.001)$ in contrast to pNGAL $(r=-0.06$; $p=0.550)$. Furthermore the MELD Na score correlated with serum creatinine $(r=0.641 ; p=0.001)$ in contrast to pNGAL $(r=-0.037 ; p=0.713)$.

\section{Discussion}

Renal impairment especially AKI is a common event in patients with cirrhosis [2, 4]. Despite the fact that serum creatinine is the standard marker of renal functions, it is a nonsensitive marker for renal dysfunction in patients with liver cirrhosis $[8,9]$. Hence searching for new biomarker is highly needed. NGAL is a promising marker that may detect early AKI. Few studies investigated the usefulness of NGAL in patients with liver diseases. The earlier studies were mainly on liver transplantation (LT) recipients.

Niemann et al. [18] evaluated the AKI in 59 patients who underwent LT. In those patients with baseline serum creatinine $<1.5 \mathrm{mg} / \mathrm{dL}$ preoperatively $(n=45)$, the baseline serum NGAL level was elevated. Measurement of intraoperative NGAL level was predictor of AKI development postoperatively. This was reinforced by Cheng et al. [20] who reported that measurement of pNGAL one hour after liver graft reperfusion was an early predictor of AKI.

Moreover Wagener et al. [21] found that urinary NGAL/ urine creatinine ratio was able to predict postoperative AKI in LT patients. Furthermore Portal et al. [22] investigated cystatin $\mathrm{C}$ and NGAL as surrogate marker of renal function in patient who underwent LT. The pNGAL predicted the development of AKI within the first 48 hours after LT with high accuracy especially in those who required renal replacement therapy.

Fagundes et al. [23] were the first ones to study the utility of uNGAL among the patients with cirrhosis $(n=241)$. There were three groups with and without ascites and with renal impairment. The last group was subdivided into prerenal azotemia, CKD, HRS, and acute tubular necrosis (ATN). The uNGAL levels were higher in patients with renal impairment especially ATN compared to none (ATN > HRS1; ATN = HRS1 with infections; HRS type I > HRS type II, CKD, and prerenal azotemia). Furthermore it was higher in patients with urinary tract infection than in those without urinary tract infection.

Verna et al. [24] investigated uNGAL in predicting mortality and identification of HRS in patients with cirrhosis $(n=$ 118). The levels of uNGAL in HRS were intermediate between prerenal azotemia and intrinsic kidney disease related AKI. Surprisingly uNGAL was predictor of the mortality and need for liver transplantation.

Barreto et al. [25] assessed the role of UNGAL in patients with cirrhosis with infection related renal impairment $(n=$ 132). In fact, uNGAL was higher in patients with AKI than in those without, persistent AKI compared to transient. In addition, uNGAL was predictor of 3-month mortality.

Notably, most of the above studies did not measure the GFR by a standard method in contrast to our study. We use the isotope scanning of the kidney for accurate measurement of the GFR. Besides we used the renal resistive index by Doppler though it was insignificant statistically.

In our study only the pNGAL level was statistically different between the groups contrary to uNGAL. As to why the uNGAL did not increase, we have no explanation and moreover Sprenkle et al. [26] found that uNGAL did not appear to be a useful marker for detecting renal injury in healthy patients treated with partial nephrectomy.

Really in our study the serum creatinine level correlated positively with the MELD and MELD Na scores and negatively with the GFR so it still is useful marker of the kidney function. It did not correlate with both pNGAL and UNGAL. The pNGAL was only positively correlated with the GFR ( $r=$ $0.3 ; p=0.001)$ despite being weak statistical correlation as $r=0.3$.

The pNGAL level was a predictor of the GFR below $60 \mathrm{~mL} / \mathrm{m}$ (odds $=0.691 ; p=0.03$ ). By using the ROC curve analysis the pNGAL level was a good positive test of high sensitivity and low specificity.

Despite these promising studies we should take into consideration also that there are some limitations with NGAL use. Most of the studies evaluated NGAL in homogeneous patients with single, acute, and easily identifiable nephrotoxic insults, such as cardiopulmonary bypass or intravenous 
contrast. NGAL appears to be less sensitive and specific in more heterogeneous cohorts with multifactorial causes for AKI [11]. The NGAL levels are elevated in CKD patients that are excluded in most studies despite being risk factor for AKI [27]. Uchino et al. [28] found that $30 \%$ of AKI patients were having CKD.

Malignancies and system infections, even simplest infection like UTI, are associated with elevated NGAL levels [11, 29]. NGAL may be more accurate in children when compared to adults who make up the vast majority of patients with AKI [11]. Finally the method of measurement may affect the results $[11,12]$.

In conclusion the pNGAL is a promising marker of the renal function in patients with liver cirrhosis.

\section{Abbreviations}

$\begin{array}{ll}\text { AKI: } & \text { Acute kidney injury } \\ \text { CKD: } & \text { Chronic kidney disease } \\ \text { CTP: } & \text { Child Pugh score } \\ \text { GFR: } & \text { Glomerular filtration rate } \\ \text { HRS: } & \text { Hepatorenal syndrome } \\ \text { MAP: } & \text { Mean arterial pressure } \\ \text { MELD: } & \text { Model of end stage liver disease } \\ \text { NGAL: } & \text { Neutrophil gelatinase-associated lipocalin } \\ \text { pNGAL: } & \text { Plasma NGAL } \\ \text { RI: } & \text { Renal resistive index } \\ \text { uNGAL: } & \text { Urinary NGAL. }\end{array}$

\section{Conflict of Interests}

The authors declare that they have no conflict of interests.

\section{Acknowledgment}

The study was funded by Science and Technology Development Fund, Egypt.

\section{References}

[1] E. A. Tsochatzis, J. Bosch, and A. K. Burroughs, "Liver cirrhosis," The Lancet, vol. 383, no. 9930, pp. 1749-1761, 2014.

[2] J. M. Belcher, C. R. Parikh, and G. Garcia-Tsao, "Acute kidney injury in patients with cirrhosis: perils and promise," Clinical Gastroenterology and Hepatology, vol. 11, no. 12, pp. 1550-1558, 2013.

[3] A. P. Betrosian, B. Agarwal, and E. E. Douzinas, "Acute renal dysfunction in liver diseases," World Journal of Gastroenterology, vol. 13, no. 42, pp. 5552-5559, 2007.

[4] N. Kamar, L. Alric, J. Izopet, and L. Rostaing, "Hepatitis C virus and kidney disease," Clinics and Research in Hepatology and Gastroenterology, vol. 37, no. 4, pp. 328-333, 2013.

[5] C. Pipili, G. Ilonidis, and E. Cholongitas, "Hepatitis C virus and kidney: a strong association with different clinical aspects," Liver International, vol. 31, no. 8, pp. 1071-1080, 2011.

[6] E. Cholongitas, V. Shusang, L. Marelli et al., "Review article: renal function assessment in cirrhosis-difficulties and alternative measurements," Alimentary Pharmacology and Therapeutics, vol. 26, no. 7, pp. 969-978, 2007.
[7] A. Davenport, E. Cholongitas, E. Xirouchakis, and A. K. Burroughs, "Pitfalls in assessing renal function in patients with cirrhosis-potential inequity for access to treatment of hepatorenal failure and liver transplantation," Nephrology Dialysis Transplantation, vol. 26, no. 9, pp. 2735-2742, 2011.

[8] C. Francoz, D. Glotz, R. Moreau, and F. Durand, "The evaluation of renal function and disease in patients with cirrhosis," Journal of Hepatology, vol. 52, no. 4, pp. 605-613, 2010.

[9] D. R. Nair, S. Mehta, and D. P. Mikhailidis, "Assessing renal function-searching for the perfect marker continues!," Archives of Medical Science, vol. 7, no. 4, pp. 565-567, 2011.

[10] D. R. Flower, A. C. T. North, and C. E. Sansom, "The lipocalin protein family: structural and sequence overview," Biochimica et Biophysica Acta-Protein Structure and Molecular Enzymology, vol. 1482, no. 1-2, pp. 9-24, 2000.

[11] D. Shemin and L. D. Dworkin, "Neutrophil gelatinase-associated lipocalin (NGAL) as a biomarker for early acute kidney injury," Critical Care Clinics, vol. 27, no. 2, pp. 379-389, 2011.

[12] M. Haase, R. Bellomo, and A. Haase-Fielitz, "Neutrophil gelatinase-associated lipocalin," Current Opinion in Critical Care, vol. 16, no. 6, pp. 526-532, 2010.

[13] S. S. Soni, D. Cruz, I. Bobek et al., "NGAL: a biomarker of acute kidney injury and other systemic conditions," International Urology and Nephrology, vol. 42, no. 1, pp. 141-150, 2010.

[14] P. Devarajan, "Neutrophil gelatinase-associated lipocalin: new paths for an old shuttle," Cancer Therapy, vol. 5, pp. 463-470, 2007.

[15] K. M. Schmidt-Ott, K. Mori, Y. L. Jau et al., "Dual action of neutrophil gelatinase-associated lipocalin," Journal of the American Society of Nephrology, vol. 18, no. 2, pp. 407-413, 2007.

[16] E. Singer, L. Markó, N. Paragas et al., "Neutrophil gelatinaseassociated lipocalin: Pathophysiology and clinical applications," Acta Physiologica, vol. 207, no. 4, pp. 663-672, 2013.

[17] M. Haase, R. Bellomo, P. Devarajan, P. Schlattmann, and A. Haase-Fielitz, "Accuracy of neutrophil gelatinase-associated lipocalin (NGAL) in diagnosis and prognosis in acute kidney injury: a systematic review and meta-analysis," The American Journal of Kidney Diseases, vol. 54, no. 6, pp. 1012-1024, 2009.

[18] C. U. Niemann, A. Walia, J. Waldman et al., "Acute kidney injury during liver transplantation as determined by neutrophil gelatinase-associated lipocalin," Liver Transplantation, vol. 15, no. 12, pp. 1852-1860, 2009.

[19] M. Bennett, C. L. Dent, Q. Ma et al., "Urine NGAL predicts severity of acute kidney injury after cardiac surgery: a prospective study," Clinical Journal of the American Society of Nephrology, vol. 3, no. 3, pp. 665-673, 2008.

[20] C.-W. Cheng, Y.-C. Chen, C.-H. Chang et al., "The ratio of plasma neutrophil gelatinase-associated lipocalin predicts acute kidney injury in patients undergoing liver transplantation," Transplantation Proceedings, vol. 44, no. 3, pp. 776-779, 2012.

[21] G. Wagener, M. Minhaz, F. A. Mattis, M. Kim, J. C. Emond, and H. T. Lee, "Urinary neutrophil gelatinase-associated lipocalin as a marker of acute kidney injury after orthotopic liver transplantation," Nephrology Dialysis Transplantation, vol. 26, no. 5, pp. 1717-1723, 2011.

[22] A. J. Portal, M. J. W. McPhail, M. Bruce et al., "Neutrophil gelatinase-associated lipocalin predicts acute kidney injury in patients undergoing liver transplantation," Liver Transplantation, vol. 16, no. 11, pp. 1257-1266, 2010.

[23] C. Fagundes, M.-N. Pépin, M. Guevara et al., "Urinary neutrophil gelatinase-associated lipocalin as biomarker in the 
differential diagnosis of impairment of kidney function in cirrhosis," Journal of Hepatology, vol. 57, no. 2, pp. 267-273, 2012.

[24] E. C. Verna, R. S. Brown, E. Farrand et al., "Urinary neutrophil gelatinase-associated lipocalin predicts mortality and identifies acute kidney injury in cirrhosis," Digestive Diseases and Sciences, vol. 57, no. 9, pp. 2362-2370, 2012.

[25] R. Barreto, C. Elia, E. Solà et al., "Urinary neutrophil gelatinaseassociated lipocalin predicts kidney outcome and death in patients with cirrhosis and bacterial infections," Journal of Hepatology, vol. 61, pp. 35-42, 2014.

[26] P. C. Sprenkle, J. Wren, A. C. Maschino et al., "Urine neutrophil gelatinase-associated lipocalin as a marker of acute kidney injury after kidney surgery," Journal of Urology, vol. 190, no. 1, pp. 159-164, 2013.

[27] D. R. McIlroy, G. Wagener, and H. T. Lee, "Neutrophil gelatinase-associated lipocalin and acute kidney injury after cardiac surgery: the effect of baseline renal function on diagnostic performance," Clinical Journal of the American Society of Nephrology, vol. 5, no. 2, pp. 211-219, 2010.

[28] S. Uchino, J. A. Kellum, R. Bellomo et al., "Acute renal failure in critically ill patients: a multinational, multicenter study," The Journal of the American Medical Association, vol. 294, no. 7, pp. 813-818, 2005.

[29] A. Yilmaz, E. Sevketoglu, A. Gedikbasi et al., "Early prediction of urinary tract infection with urinary neutrophil gelatinase associated lipocalin," Pediatric Nephrology, vol. 24, no. 12, pp. 2387-2392, 2009. 


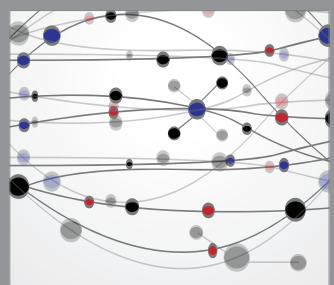

The Scientific World Journal
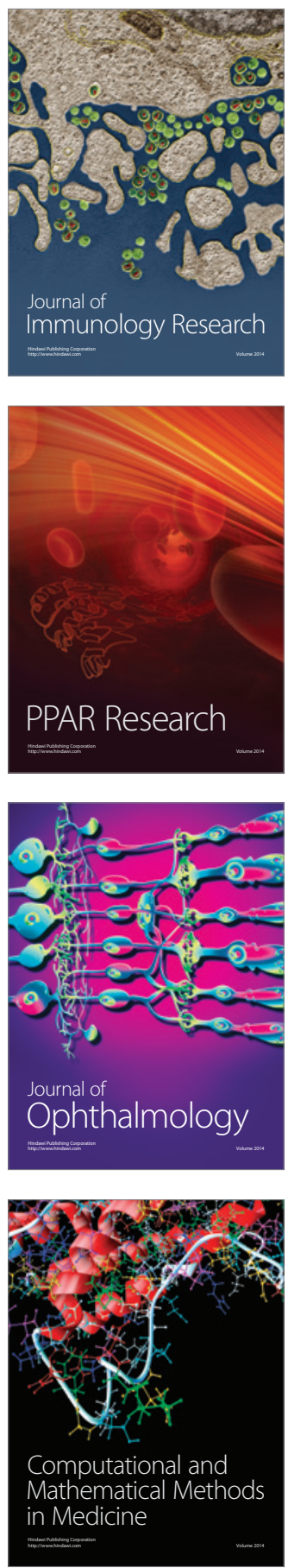

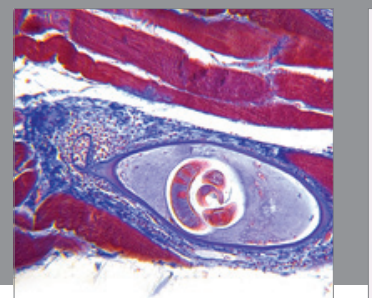

Gastroenterology

Research and Practice
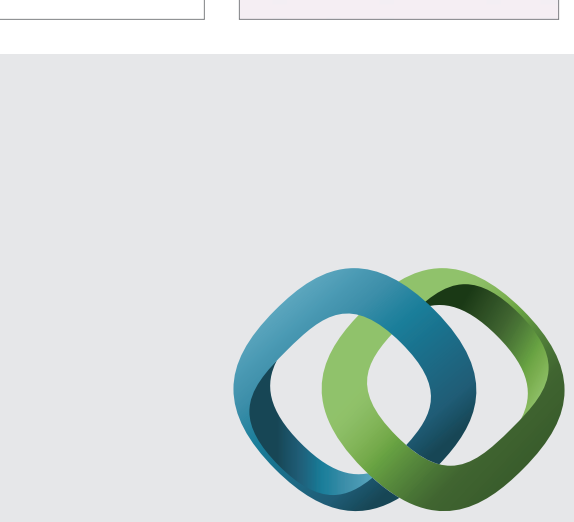

\section{Hindawi}

Submit your manuscripts at

http://www.hindawi.com
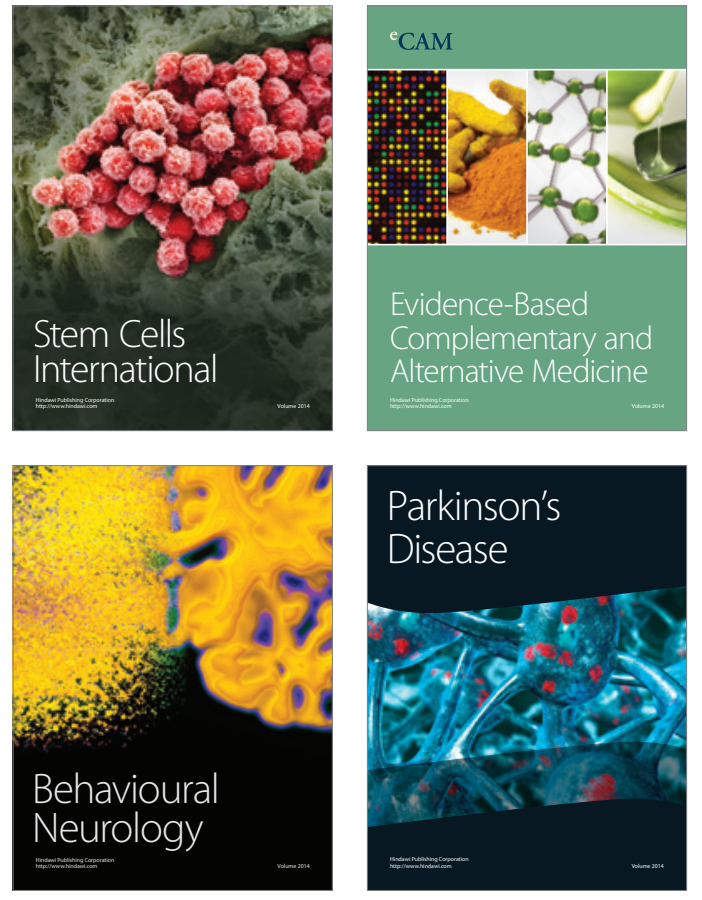
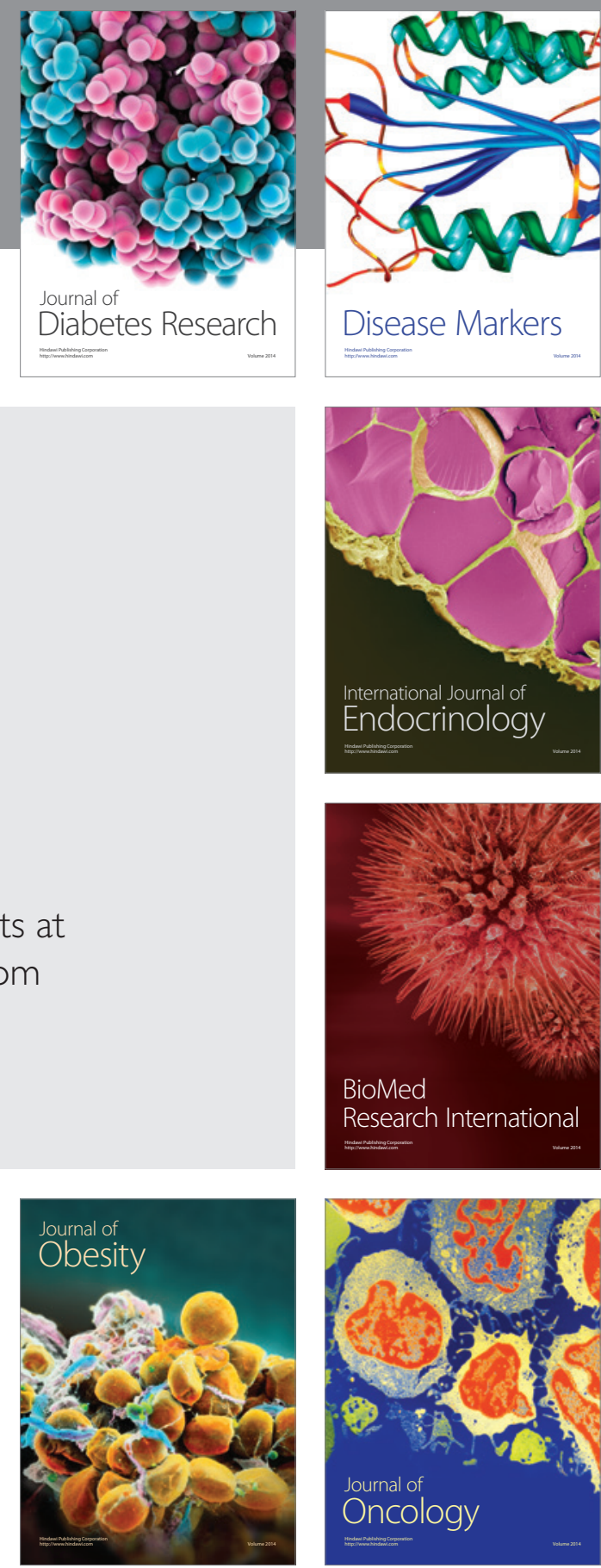

Disease Markers
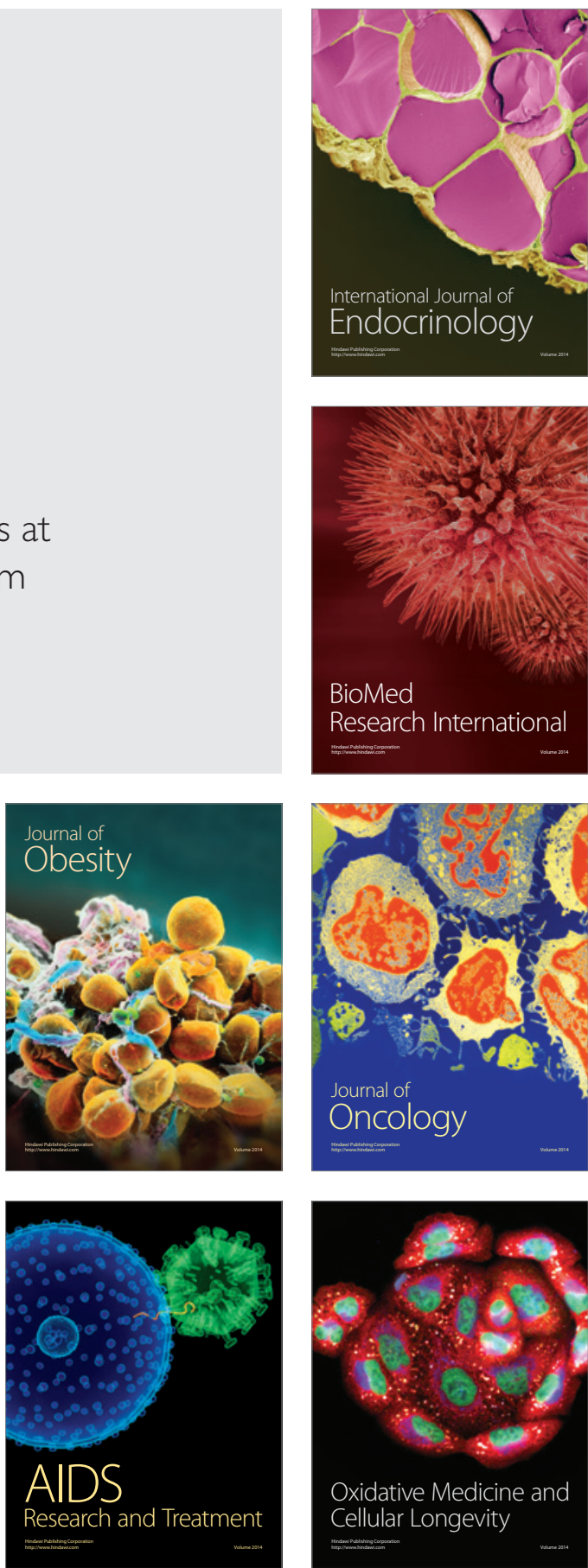